\title{
Cada uno es responsable
}

Keywords: legislación; europea; internacional

Los días 29 de febrero y 1 de marzo (2011), se ha presentado en Bruselas la nueva estrategia de la UE, en tema de Protección y Bienestar Animal, cuyas directrices principales serán el motor de los cambios que se introduzcan en la materia en los próximos años.

La presidencia de Dinamarca en este bienio, ha impulsado la celebración de un Congreso Internacional, del que ya hemos adelantado algunas noticias [1], que ha constituido un acontecimiento del máximo interés para especialistas y para el público general, pues el acento de la nueva estrategia europea se basa en el principio de que "cada uno es responsable” (everyone is responsible”).

El último eslabón de la cadena de responsabilidades -determinantes de una mejora en el trato de los animales-, es el individuo, sea cual sea su posición y su ocupación en la sociedad. Por ello, es especialmente interesante que el Congreso se refiriera concretamente a cómo acrecentar y reforzar el poder de los consumidores, como proveerlos de una información fidedigna de cómo se ha realizado la cría y el desarrollo de los animales -de producción especialmente-; de ahí el título del evento: "Capacitar a los consumidores y crear de oportunidades de mercado para el Bienestar Animal” ("Empowering consumers and creating market opportunities for animal welfare”).

El significado de esta estrategia reside en dos propósitos centrales, producto de la experiencia acumulada a lo largo de estos años en que la UE, ha ido trazando un complejo sistema legislativo, basado en priorizar el bienestar animal desde bases científicas. Tales propósitos son: por un lado, el deseo de que en los próximos cuatro años, los avances científicos y tecnológicos en tema de bienestar animal se concilien con las realidades de mercado -por cierto, global- y , por otro lado que la legislación relativa aporte mayor transparencia en los mercados permitiendo, entre otras novedades, una mayor flexibilización y adaptación de la legislación marco, a las realidades legislativas de los Estados Miembros.

La nueva estrategia, pues, trata de activar dos acciones complementarias, que pueden resumirse: en primer lugar, en revisar los principios generales de la legislación marco europea en tema de bienestar animal, perfectamente consolidados, pero necesitados de simplificación, de forma que el bienestar de los animales se refuerce, pues el acercamiento de las normas a los productores y consumidores redundará en un refuerzo y una mejora de su aplicación y control. En segundo lugar, la Comisión reconoce que existen reformas que precisan ser reforzadas o mejor usadas, para que sean realmente eficaces. Se trata de hacer un ejercicio de transparencia para que la información de productores y actores implicados en la salud pública, la cadena alimentaria y el consumo, llegue de forma sencilla y directa al consumidor, para que éste pueda realizar elecciones responsables.

La cooperación internacional de todos los actores implicados, es indispensable para que tenga éxito este nuevo avance. Porque, en definitiva, son los animales los que nos importan y es por ellos por quienes se deben hacer, desde todos los ángulos, los esfuerzos que sean necesarios para que la legislación europea no quede como un monumento a la erudición y al detalle prolijo, sino que alcance a la conciencia individual y a la responsabilidad corporativa de las empresas. Cada uno de nosotros debe verse y actuar como responsable del bienestar de los animales. No somos meros espectadores. 
Catedrática de Derecho Romano

Animal Law Profesor

Universitat Autònoma de Barcelona

[1] Conferencia internacional acerca de la nueva'Estrategia de la UE en Bienestar Animal 2012-2015', Bruselas, 29 de febrero a 1 de marzo; WARTENBERG, M., La nueva estrategia de bienestar animal de la UE 2012-2015 - Un cambio de paradigma en la política europea de bienestar animal 